Panajotta Lakkis

\title{
Gestaltungsakte im internationalen Rechtsverkehr
}

Zur prozessualen Bindung an in- und ausländische privatrechtsgestaltende Urteile und andere privatrechtsgestaltende Hoheitsakte

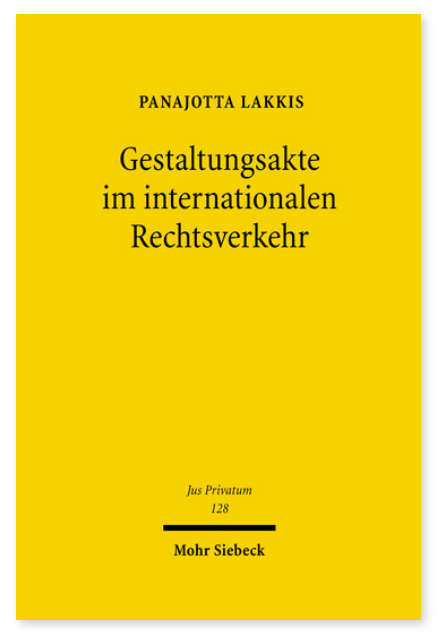

2007. XIV, 505 Seiten. JusPriv 128

ISBN 978-3-16-151205-6

DOI 10.1628/978-3-16-151205-6

eBook PDF 149,00€

ISBN 978-3-16-149077-4

Leinen $149,00 €$
Panajotta Lakkis widerlegt die seit jeher bestehende Annahme, es bestünde eine prozessuale Gestaltungswirkung, die inter omnes gelte. Hat man bisher die inter omnes-Wirkung ungeprüft zu Grunde gelegt und sich nur mit den Folgeproblemen befasst, namentlich mit der Problematik des rechtlichen Gehörs, geht die Autorin den umgekehrten Weg und hinterfragt die Prämisse. Sie zeigt, dass es gar keine eigenständige prozessuale Gestaltungswirkung gibt, sondern dass die einzige maßgebliche prozessuale Bindungswirkung auch der Gestaltungsurteile die materielle Rechtskraft ist. Dies bedeutet auch, dass die subjektiven Grenzen der Bindung an ein Gestaltungsurteil nur von der materiellen Rechtskraft bestimmt werden. Die Hauptargumentation für die bisherige Annahme einer inter omnes-Wirkung, dass nämlich begriffsnotwendig eine Gestaltung entweder erfolgt sein kann oder eben nicht, wird an Hand der Parallele zur 'einfachen' materiellrechtlichen Gestaltung mit anschließender rechtskräftiger Feststellung widerlegt. Nachdem die dogmatische Basis gesetzt ist, geht die Autorin zur Betrachtung anderer hoheitlicher Gestaltungsakte über und sieht darin ihre These von der Maßgeblichkeit der materiellen Rechtskraft bestätigt. In einem zweiten Teil wird dann die Problematik auch im grenzüberschreitenden Rechtsverkehr dargestellt. Abschließend findet sich eine ausführliche Zusammenfassung, die die Möglichkeit gibt, sich in komprimierter Form mit der These vertraut zu machen.

Panajotta Lakkis Geboren 1970; Studium der Rechtwissenschaften und Refendariat in Thessaloniki (GR); 1996 Promotion; 2005 Habilitation; 2006-2007 Lehrstuhlvertretung in München, 2007/2008; Lehrstuhlvertretung in Erlangen

Jetzt bestellen:

https://mohrsiebeck.com/buch/gestaltungsakte-im-internationalen-rechtsverkehr-9783161512056?no_cache=1

order@mohrsiebeck.com

Telefon: +49 (0)7071-923-17

Telefax: +49(0)7071-51104 